DOI: $\underline{10.20472 / B M .2020 .8 .2 .004}$

\title{
POSITION IN INTER-ORGANIZATIONAL NETWORKS AND PROFITABILITY AND GROWTH POTENTIAL
}

\section{FUMIHIKO ISADA}

\begin{abstract}
:
The purpose of this study is to empirically clarify the relationship between a company's position in the network structure of inter-company collaboration and its profitability and growth potential. In particular, by categorizing and analyzing companies located at the center of the network, we attempted to gain insight into the generation and growth process of so-called platformer companies. According to previous research, companies that are at the center of collaboration among various companies vary by industry and product characteristics. This research focuses on the Internet of Things (IOT), which is an industry in which inter-business relationships are important for collecting and utilizing big data across industries as an object of analysis. As a research method, we extracted the text information of newspaper articles related to loT and analyzed the transition of the relationship between companies using social network analysis. Network analysis based on newspaper article data showed the possibility of one process to grow from a niche company to a platform leader and eventually to a large company.
\end{abstract}

\section{Keywords:}

Inter-organizational network; Platform leadership; Business Ecosystem; Social network analysis; Internet of Things

JEL Classification: M11, 032, L14

\section{Authors:}

FUMIHIKO ISADA, Kansai University, Japan, Email: isada@kansai-u.ac.jp

\section{Citation:}

FUMIHIKO ISADA (2020). Position in inter-organizational networks and profitability and growth potential. International Journal of Business and Management, Vol. VIII(2), pp. 73-85., 10.20472/BM.2020.8.2.004 


\section{Introduction}

In recent years, there has been an increase in the number of researches on the relationship between inter-organizational relationships and growth and profitability, including platform leadership theory (Gawer \& Cusumano, 2002) and business ecosystem theory (lansiti \& Levin, 2004). In other words, growth and profitability are not only determined by the superiority of a firm's own products and services, but also by its inter-organizational relationships with external firms.

For example, in the IT industry, companies such as so-called platformers (hereafter, platform leaders) are growing rapidly. In the IT industry, more independent and diverse specialized companies are collaborating horizontally than in industries such as heavy chemicals and automobiles. Therefore, it is assumed that the way of cooperation among various companies has a great impact on the growth and profitability of a company. The platform leaders mediate the relationships among many diverse firms. Platform leaders tend to have high growth potential due to network externalities. Therefore, many venture firms are competing for the position of the platform leader. If the process for a venture firm to become a platform leader is clarified, it would be significant in both research and practice. In addition, there are some firms that are not platform leaders but are highly profitable. For example, a niche company that has a unique product or technology that complements the platform leader. Furthermore, there are many cases of platform leaders that have high growth potential but not high profitability. Therefore, it is necessary to analyze growth and profitability separately.

In this study, inter-firm relationships were analyzed as a network structure surrounding the firms. The relationship between the position of each company in the network and its growth and profitability was analyzed quantitatively. As a method of analysis, social network analysis was applied. As a target of analysis, the Internet of Things (IOT) industry was chosen because it is a relatively new industry and there is not much previous research on it.

First, according to previous studies, it was hypothesized that inter-organizational relationships in the loT industry have a significant impact on the growth and profitability of companies, similar to the IT industry. Also, according to previous studies such as Platform Leadership and Business Ecosystem, hypotheses about the position in the inter-organizational network affecting growth and profitability were established. Then, a database of inter-organizational relations was constructed based on newspaper articles, and the social network analysis method was used to calculate the positional indices of each company in the network. Finally, each hypothesis was verified based on the correlation analysis between each network indicator and growth and profitability. In addition, the growth process of the platform leaders was discussed.

\section{Previous Research}

\section{$2.1 \quad$ loT Business}

According to Porter and Heppelmann (2014), the phrase "Internet of Things" has arisen to reflect the growing number of smart, connected products and to highlight the new opportunities they can present. However, this phrase is not very helpful in understanding the phenomenon or its implications. The Internet, whether involving people or things, is simply a mechanism for transmitting information. What makes smart, connected products fundamentally different is not 
the Internet but the changing nature of the "things." It is the expanded capabilities of smart, connected products and the data they generate that are ushering in a new era of competition. Companies must look beyond the technologies themselves to the competitive transformation taking place.

Moreover, according to Porter and Heppelmann (2015), the new capabilities of smart, connected products alter every activity in the value chain. Data is at the core of reshaping the value chain. As the ability to unlock the full value of data becomes a key source of competitive advantage, the management, governance, analysis, and security of data are developing into major new business functions.

Data is a scarce resource which can serve as a source of a competitive advantage as a characteristic of loT business, and it is thought that the business system centering on data improves competitive advantage. The increasing capabilities of smart, connected products not only reshapes competition within industries but also expands industry boundaries. This occurs as the basis of competition shifts from discrete products to product systems consisting of closely related products, which in turn shifts to systems of systems that link an array of product systems together (Porter \& Heppelmann, 2014).

\subsection{Platform Leadership}

According to Gawer and Cusumano (2002), platforms are the product and service that act as a base on which multiple complementary companies make a product or provide a service. The company that manages such a platform is called the platform leader. The characteristic strategies for a platform leader to lead its own platform to success are classified into four categories: the clarification of the business scope, the open/closed design, the relationship with an external complementary company, and the design of the inner structure (Gawer \& Cusumano, 2002).

To gather complementary companies, it is important for a platform leader that the network externality (Katz \& Shapiro, 1985) works well. The network externality stimulates the participation of complementary companies, and the increase in the number of participating complementary companies raises the network externality. For that purpose, it is important for a platform to solve the substantial problem of the system and to support the strong relation of interdependence between the platform and the complementary goods (Gawer \& Cusmano, 2008). Furthermore, this viewpoint develops into the view of a two-sided market (Rochet \& Tirole, 2003). In the case of a platform for two kinds of markets, such as a dealer and consumers, the indirect network externality between each market is caused by a suitable price strategy, and the competitiveness of the platform is strengthened.

In addition, according to Gawer and Cusumano (2008), so that the users of a platform cannot easily move to a competing platform, it is important to raise an incentive and switching cost. It is necessary for a platform leader not to require a profit hastily but to make prior investments in an industry standard, to open the technical specifications appropriately, and to build a fiduciary relation with complementary companies (Gawer \& Cusumano, 2002).

According to Farrell and Klemperer (2007), switching costs and network effects bind customers to vendors if products are incompatible, locking customers or even markets into early choices. Lockin hinders customers from changing suppliers in response to (predictable or unpredictable) changes in efficiency and gives vendors lucrative ex-post market power over the same buyer in the case of switching costs (or brand loyalty) or over others with network effects. 


\subsection{Business Ecosystem}

Gawer and Cusumano (2013) define external or industry platforms as products, services, or technologies, developed by one or more firms, which serve as foundations upon which a larger number of firms can build further complementary innovations in the form of specific products, related services, or component technologies. Industry platforms tend to facilitate and increase the degree of innovation in complementary products and services. The greater the innovation in such complementary aspects, the greater the value created for the platform and its users via network effects, creating a cumulative advantage for existing platforms. As these grow, they become harder for rivals or new entrants to dislodge; the growing number of complements acts as a barrier to entry. Highlighting the complex trade-offs between "open" and "closed" innovations, Gawer and Cusumano (2008) suggest that while opening up interfaces will increase complementors' incentives to innovate, it is important to preserve some source of revenue and profit as proprietary.

According to lansiti and Levien (2004), there are three classes of companies within the business ecosystem: keystone, dominator, and niche player. lansiti and Levien (2004) note the role of the "keystone firm," one that drives industry-wide innovation for an evolving system of separately developed components. Keystone and dominator strategies can be pursued by firms that occupy important hubs in their business networks. Niche strategies can be pursued by the much larger number of firms that make up the bulk of the ecosystem. They emphasize differentiation by focusing on unique capabilities and leveraging key assets provided by others. By being part of several competing networks, niche players can use the threat of leaving to keep keystones honest and to enjoy profitability.

\subsection{Social Network theory}

The aforementioned platform leadership theory and ecosystem business theory can be explained by social network theory. Social network analysis is the process of investigating social structures using network and graph theories (Otte \& Rousseau, 2002). It characterizes networked structures in terms of nodes (individual actors, people, or things within the network) and the ties, edges, or links (relationships or interactions) that connect them. Examples of social structures commonly visualized through social network analysis include social media networks (Grandjean, 2016), message propagation in a social network service (Nasrinpour \& Friesen, 2016), friendship and acquaintance networks, collaboration graphs, kinship, disease transmission, and sexual relationships (D'Andrea, Ferri, \& Grifoni, 2010; Pinheiro, 2011). These networks are often visualized through sociograms in which nodes are represented as points and ties are represented as lines. Network features can be at the level of individual nodes, dyads, triads, ties and/or edges, or the entire network. For example, node-level features can include network phenomena such as betweenness and centrality or individual attributes such as age, sex, or income (Hanneman \& Riddle, 2005).

According to Kilduff \& Brass (2010), homegrown theories, developed within the social network research tradition, have included the strength of weak ties and structural holes. According to Granovetter (2005), more novel information flows to individuals through weak rather than strong ties. As close friends tend to move in the same circles, the information they receive overlaps considerably with what is already known. Acquaintances, in contrast, know people in other circles and thus receive more novel information. Burt (2004) classifies ties into Bridging Ties and Cohesive Ties, and Bridging Ties are defined as ties that connect separated individuals and 
groups. These can be analysed by indexes such as the number of intervening ties and structural holes. When there is no direct connection between those who are connected to the actor (ego), a structural hole is said to exist between them. Bridging Ties' strength lies in the widespread dissemination of new, formal, and heterogeneous knowledge, and it is easily linked to radical innovation.

And there have been empirical studies in various industries on the impact of these network structures on firm performance. For example, Rowley et al (2000) show that in the fast-changing semiconductor industry, firms with more weak ties tend to increase their performance. The same causal relationship is analogous to the growth of platform leader firms in the IT industry. The main strategic challenge for platform leaders is to grow by increasing their weak ties with as many, and in some cases as many strangers, as possible, via open technical standards, etc. Vissa \& Chacar (2009) analyzed the external networking of startups in the Indian software industry. They showed that the richer the structural holes around the team, the higher the sales growth rate of the firm. On the other hand, Rowley et al (2000) also conducted an empirical study of the slow-changing steel industry and, conversely, found that firms with richer strong ties tend to perform better. In other words, if growth is important, then increasing the number of weak ties is effective, while if profitability is important, then increasing the number of strong ties is effective.

\subsection{Diffusion of Innovations}

Diffusion of innovations is a theory that seeks to explain how, why, and at what rate new ideas and technology spread. The theory was popularized by Rogers (1962), who argues that diffusion is the process by which an innovation is communicated over time among the participants in a social system. Diffusion is highly subject to the type of adopters and innovation-decision process. Rogers defines an adopter category as a classification of individuals within a social system based on innovativeness, defined as the degree to which an individual adopts a new idea. Rogers suggests a total of five categories of adopters to standardize the usage of adopter categories in diffusion research. The adoption of an innovation follows an S-curve when plotted over a time course. Within the rate of adoption, there is a point at which an innovation reaches critical mass.

Moore (1991) uses this technology adaptation life cycle as a framework in high-tech products. The gap between the early adopters and the late adopters was pointed out, and the procedure for overcoming the gap was shown. First, it is important to focus on niche markets because it is easier to dominate them. It is advised to divide the market into segments, analyze each segment (size, accessibility to distribution, etc.), and pick one to establish a monopoly in your niche market. Next, to exceed the critical mass, whole produce is to be prepared, which consists of generic products, expected products, augmented products, and potential products. Consumers on the left with the Technology Adoption Life Cycle (the visionaries and the techies) are the ones who need whole product support. Pragmatic customers, on the other hand, prefer the whole product. They like standardization that enables software to run. If they have to buy things piecemeal, they will - but as soon as there is a better option, they are all over it. This whole product model is a key to successfully negotiating the chasm between the early adopters and the early majority. Whole product planning is the key to market dominance. There is much to say for working with partners. Whole product alliances can facilitate the whole product by coordinating production schedules and other functions, and they work because they are in both companies' best interest. They are tactical through a value chain. 
According to Moore (2014), in the high-tech industry and B2B market, some companies that provide services mainly via the Internet are rapidly diffusing their services without going through a chasm in a different way from traditional market penetration processes. For example, advanced companies related to information technology such as Google, Facebook, YouTube, and Skype overcame competition by gaining user support and spread quickly without going through the chasm. In the case of products where the network externality works strongly, companies tend to neglect the immediate profit and try to acquire users and complementary operators through low price competition to exceed critical mass. Even if earnings cannot be obtained temporarily, it can be regarded as an upfront investment for future profit acquisition.

One example of such a price competition strategy is the idea of "freemium." In the business model of freemium, basic products and services are provided free of charge and spread, while some high-performance products and services are charged as premium (Iglesia \& Gayo, 2009). Reime (2011) conducted a case study of a freemium business model using cloud computing and extracted nine features found in freemium (user acquisition channel, lock-in effect, transition rate from free users to premium users, etc.).

\section{Research Hypothesis}

Based on previous research, we categorize companies that are at the center of the loT industry's inter-organizational network and make hypotheses about their profitability and growth potential.

According to previous research on loT, although the technical capabilities of individual devices, hardware, and software are of course important, as a characteristic of loT-related businesses, the source of business revenue is a cross-cutting database generated, collected, and utilized through collaboration among various companies. Therefore, locating on the collaboration network to be advantageous in constructing a cross-cutting database can be a source of competitive advantage. According to previous research on platform leadership, the network externality by the spread of its own interface standard is important for the growth strategy of the company aiming at the platform. An important goal of the growth strategy is to increase the use of its products and services by more customers and complementary operators throughout the industry. Therefore, it is important to properly distinguish the business area from complementary companies, to concentrate management resources on the company's special business area, and to build a good cooperative relationship with the complementary companies. Assuming the layer structure of various products and services such as hardware, software, and networks that make up a product, if the company can take positions that mediate each layer, the switching cost increases. To take such a position, it is necessary to make upfront investments to create relationships with various complementary operators in other layers.

According to previous research on the ecosystem, the incentive for the players of various layers to adopt their products is the growth of the entire ecosystem - that is, the increase of customers and sales and the promotion of innovation of participating companies. The same thing has been pointed out in previous research on keystones, and the role of the keystone company (equivalent to a platform leadership company) in the ecosystem is the sound development of the whole ecosystem. The degree to which the participating companies' innovation is promoted is an indicator of the productivity of the ecosystem. Conversely, if an enterprise pursues only its own profit in the ecosystem, it cannot build a good relationship with other participating companies, and the entire ecosystem does not develop. 
Previous research also mentions the role and advantage of niche companies in the ecosystem. Niche companies complement centrally positioned keystone companies in the development of the ecosystem. Also, niche companies can participate in multiple ecosystems and collaborate with their keystone companies if they can be differentiated by their own technologies. The niche companies that are required by multiple keystone companies will increase their bargaining power and become more profitable even if they are not platform companies. Also, such a competitive niche company might have an exit strategy to be bought out but have the potential to become a platform company in the future.

According to previous research on innovation diffusion, to become a platform company, it is necessary to go through the stages of diffusion. According to previous research on diffusion of high-tech products, the diffusion strategy must be transformed between the early and the growth stages of the life cycle. In the first stage, niche companies start by defining business domains and proposing technology to gain the support of important target customers. Next, it is important to increase the occupancy rate in niche markets by preparing the necessary complementary products and services through collaboration with other companies. In other words, increasing market share in niche markets can be interpreted as implying platform formation. Expansion in the horizontal direction to be a platform has a higher priority for growth than diversification and integration in the vertical direction. To increase the market share, it is important to work with related complementary companies. As mentioned above, it is useful to strengthen the incentives for complementary companies and to accelerate the growth rate even if the immediate profit is overlooked. After that, if a company can gain a solid market share as a platform leader, it can be used by accumulating big data, which is an important source of earnings in the loT market, and expanding into diverse businesses in multiple directions. It is considered that high profitability can be realized.

From the above examination, the following hypotheses can be derived for profitability and growth potential for each type of company located at the center of the inter-organization network in the loT industry.

Hypothesis 1: The more a firm collaborates with core firms, the more profitable it is (niche firms).

Hypothesis 2. The more a firm mediates through multiple other firms, the greater its growth potential, but not necessarily its profitability (platform leader)

Hypothesis 3: The more a firm collaborates with outside firms, the more profitable it is (large firms).

\section{$4 \quad$ Methodology}

To verify each of the hypotheses mentioned above, the data of collaboration among companies were collected and constructed a database for analysis. Then, the database was analyzed using social network analysis, and the network index representing the relationship between companies was calculated. Finally, the relationship between each network indicator and financial information of each company was analyzed.

\subsection{Data}

First, to verify the relationship between companies related to loT business, in this research, data were extracted from newspaper articles. The information source was the Nihon Keizai Shimbun, the largest newspaper in Japan as an economic newspaper, and newspaper articles were 
extracted using the database of the Nikkei Telecon service contracted by my working school. The newspaper article extraction condition is an article that contains loT as a keyword and is an article on collaboration between multiple companies. The company names were extracted from each article.

The extraction period was from April 2015 to March 2018. (In Japan, the year of many companies runs from April until March of the following year.) The keyword loT is relatively new; it has been about five years since it began appearing in newspapers, and it has been common since 2015 . Therefore, changes from 2015 until recent years were analyzed. The companies listed in those articles were analyzed with social network analysis. The indicators used in the social network analysis will be described in the next section.

Next, growth potential and profitability were compared between companies. Before comparison, the goal of this research is to analyze the relationship between companies, so companies that hardly cooperate with other companies were excluded from comparison. Companies appearing in multiple articles and working with multiple companies were selected. Those companies are likely to play an important role among corporate networks such as platform leader companies. To compare growth potentials, only companies for which it is possible to continuously collect financial information from the fiscal year 2015, the first year of the analysis period, were extracted.

In addition, when comparing growth potential and profitability, if there is a difference in general growth potential and profitability in the original industry, there is a concern that the difference could affect the analysis results. Therefore, comparisons were made between companies within the same industry. The extracted companies were classified according to the industry classification defined by the Tokyo Stock Exchange of Japan, and the industries including several loT-related companies were extracted.

\subsection{Analytical methodology}

This section addresses the analytical methodology and indicators of social network analysis used for verification of the hypotheses in this research. Regarding the aforementioned hypotheses, of the various indicators employed in social network analysis, "degree centrality" was used as an indicator of network breadth. In graph theory and network analysis, indicators of centrality identify the most important vertices within a graph. Applications include identifying the most influential person(s) in a social network, key infrastructure nodes in the Internet or urban networks, and super-spreaders (of disease). Centrality concepts were first developed in social network analysis, and many of the terms used to measure centrality reflect their sociological origin (Newman, 2010). Degree centrality is defined as the number of ties related to a node. UCINet (https://sites.google.com/site/ucinetsoftware/home) calculates the degree and normalized degree centrality of each vertex and provides the overall network degree centralization. The number of vertices adjacent to a given vertex in a symmetric graph is the degree of that vertex. For nonsymmetric data, the in-degree of a vertex $u$ is the number of ties received by $u$, and the outdegree is the number of ties initiated by $u$. In addition, if the data are valued, the degrees (in and out) will consist of the sums of the values of the ties. The normalized degree centrality is the degree divided by the maximum possible degree expressed as a percentage.

Next, "eigenvector centrality" was used as an indicator of niche positioning. Eigenvector centrality is a measure of the influence of a node in a network (Bonacich, 1987). It assigns relative scores to all nodes in the network based on the concept that connections to high-scoring nodes contribute more to the score of the node in question than equal connections to low-scoring nodes. 
The eigenvector centrality thesis states that a node is important if it is linked to other important nodes. Eigenvector centrality is also a ranking measure (Leontief, 1941). Actors who are tied to very central actors should have higher prestige/centrality than those who are not. UCINet (https://sites.google.com/site/ucinetsoftware/home) calculates the eigenvector of the largest positive eigenvalue as a measure of centrality.

In addition, "betweenness" was used as an indicator of the style of network platform. Betweenness is an aspect of the larger concept of "centrality." An ego is "between" two other actors if it lies on the shortest direct path from one to another. The ego betweenness measure indexes the percentage of all geodesic paths from neighbor to neighbor that pass through the ego. Normalized betweenness compares the actual betweenness of the ego and the maximum possible betweenness in the neighborhood of the size and connectivity of the ego. The "maximum" value for betweenness would be achieved in the case that the ego is at the center of a "star" network; that is, no neighbors communicate directly with one another, and all communications between pairs of neighbors go through the ego. UCINet (https://sites.google.com/site/ucinetsoftware/home) computes the sum of the proportion of times the ego lies on the shortest path between each pair of actors. For actors connected to each other, the contribution between the pair is 0 . For actors connected to each other only through the ego, the contribution is 1 . For actors connected through the ego and one or more other actors, the contribution is $1 / \mathrm{k}$, where $\mathrm{k}$ is the number of nodes connecting that pair of actors. UCINet (https://sites.google.com/site/ucinetsoftware/home) computes ego betweenness (nEgoBetween) normalized by a function of the number of nodes in the ego network. The notions of "betweenness" are differing ways of indexing just how "central" or "powerful" the ego is within its own neighborhood. This aspect of how an actor's embedding might provide strategic advantage has received a great deal of attention.

Social network analysis software generates these features from raw network data formatted as an edge list, adjacency list, or adjacency matrix (also called a sociomatrix), often combined with (individual/node-level) attribute data (Hanneman \& Riddle, 2005). Although the majority of network analysis software uses a plain text ASCII data format, some software packages contain the capability to use relational databases to import and/or store network features. Network analysis software generally consists of either packages based on graphical user interfaces (GUIs) or packages built for scripting/programming languages. In general, GUI packages are easier to learn, while scripting tools are more powerful and capable of extension. Widely used and welldocumented GUI packages include NetMiner, UCINet, Pajek (freeware), GUESS, ORA, Cytoscape, Gephi, SocNetV (free software), and muxViz (open source). In this research, UCINet 6 for Windows was used.

\section{$5 \quad$ Results of Analysis}

A total of 1,198 newspaper articles related to collaboration between two or more companies related to IoT were extracted. For the companies listed in the extracted articles, the aforementioned network indicators were calculated based on the method of social network analysis. Next, 139 companies that were linked with multiple companies and for which it was possible to analyze financial information in time series were extracted. Performance such as growth and profitability is influenced by external factors such as the industry to which the company belongs, in addition to the internal factors of each company. 
If various industries coexist in comparing the network index of each company with growth and profitability, the difference between the industries will affect the analysis results. Therefore, the analysis target was narrowed down by industry. Of 139 companies, when classified according to the industry classification of the Tokyo Stock Exchange, the industry with the largest number of companies is the information and communications industry, which has 34 companies. Therefore, based on the financial reports of each of these 34 companies, the operating profit margin in the fiscal year 2017 and the rate of increase in operating profit from 2015 to 2017 were calculated as financial indicators. The result of analyzing the correlation between the network indicators and the financial indicators is as shown in Table 1.

Table 1. Correlation analysis result between the network indicator and the profit indicator

\begin{tabular}{|c|l|l|}
\hline Network indicator & \multicolumn{1}{|c|}{ Profit rate } & Profit increase rate \\
\hline Degree Centrality & $0.38^{\star}$ & 0.12 \\
\hline Eigenvector Centrality & $0.38^{\star}$ & 0.18 \\
\hline Betweenness (nEgoBetween) & -0.23 & $0.42^{*}$ \\
\hline
\end{tabular}

(The numerical value is the correlation coefficient, ${ }^{*} p<0.05$ )

\section{Considerations}

According to the analysis results, degree centrality, eigenvector centrality, and betweenness are inversely related to financial indicators. Both degree centrality and eigenvector centrality had a significant positive correlation with profitability at one time point, but they had no correlation with growth potential. On the other hand, while betweenness had a significant positive correlation with the growth potential from the past, it did not correlate with the profitability at one time point. Each hypothesis is assumed to be fully supported.

A large value of degree centrality indicates that the company cooperates with many other companies, and it is assumed that such a company is large in size. The large value of eigenvector centrality indicates that the company does not necessarily cooperate with many other companies but cooperates with large companies with a large amount of cooperation. Such companies are assumed to be niche companies that supply scarce products and services, and centrally positioned companies want such companies to work together. It is assumed that large companies with economies of scale or niche companies that can be differentiated by special technology are all highly profitable.

As a case study of the individual companies that are the subject of this analysis, software companies for specific applications were classified as niche companies. For example, a company that possesses advanced Artificial intelligence (Al) technology and provides software and solutions for analyzing databases used for loT. The market size is not necessarily huge, but it supplies the products and services that platform leader companies and large companies that have databases want. It is difficult to substitute due to advanced technology, and high profitability is realized. On the other hand, for niche companies to grow, there must be a strategy to grow. To grow, it is thought that the strategy regarding the position taking on the network is effective. 
Also, as a case study of the individual companies, diversified companies, such as those that provide everything from communication infrastructure to enterprise solutions, were classified as large companies. In the case of telecommunication infrastructure, the barriers to entry are high because it requires huge investments, and firms that originally own assets have a first-mover advantage and are highly profitable. On the other hand, large companies do not always have high growth potential. For example, the growth rate of the infrastructure itself is not necessarily as fast as that of the services that use the infrastructure.

A large value of betweenness indicates that the company is a position that mediates collaboration between other companies. It is assumed to be in a position called a platformer or a platform leader such as an operating system in a computer, and a trading platform in electronic commerce. According to the analysis results, the company in the position of platform leader is not always highly profitable but has high growth potential.

As a case study of the individual companies that are the subject of this analysis, companies that provide databases and related middleware for the loT were classified as platform companies. These companies provide products that are essential for loT, and they are growing with the expansion of the loT business. On the other hand, their profitability is low because the competition is fierce, and they invest the profits they earn in scale and marketing upfront. The competition for the position of platform leaders is often intense, and continuous upfront investment is required to win inter-standard competition with competitors and to gain many complementary partners. It is necessary to invest not only in the company's technology but also in creating relationships with complementary businesses and to expand the company's ecosystem by properly dividing the business area with vertical complementary businesses, respecting the win-win relationship, and promoting innovation together while expanding rapidly in the horizontal direction.

Next, based on the above analysis results, we consider the generation and growth process of a platform leader company. When newly entering as a venture company, it is thought that it is easy to succeed by first establishing a strong relationship with existing leading companies as a niche company with unique products and services. As a growth strategy of a niche company, the first is to aim for growth not in the vertical direction to other business domains but in the horizontal direction in the same business area. The second is to make an upfront investment in strategically attracting customers and complementary businesses. As a result, companies that have survived severe competition and have established a solid platform leader position promote related diversification and vertical integration into profitable business areas to gradually increase profitability. In summary, a series of growth processes can be analogized, leading to success as a niche company, horizontal growth to form a platform, and eventually high profitability as a large company.

In the case of the aforementioned Al technology companies, the next stage of growth should be the expansion of the applications of the technology. Vertical growth, such as hardware, is undesirable. In the case of the database company, which is a case of the platform company mentioned above, it should focus on the expansion of the ecosystem that uses its database. And beyond a certain critical mass, when network externalities come to work strongly, it is desirable to gradually grow vertically into related services and hardware. 


\section{CONCLUSIONS}

The goal of this research is to empirically clarify the profitability and growth potential of the company that is the center of the collaboration using actual data in the loT business, where business collaboration strategies are important. From the analysis results, we gained insight into the growth process of platform leader companies. Network analysis based on newspaper article data showed the possibility of one process to grow from a niche company to a platform leader and eventually to a large company.

As an implication of this research result, the result is expected to be an effective suggestion for the strategic planning of a company that aims to grow in an advanced business like loT. The development of cutting-edge businesses is also an important task for government policymakers.

The limitations of this research are the problem of data reliability due to using newspaper article information as the original data and the issue of validity of the analysis centered on the case of Japanese companies. As future research subjects, complementation with other databases, survey methods, and international comparative research can be considered.

\section{$8 \quad$ References}

Bonacich, P. (1987). Power and centrality: A family of measures. American Journal of Sociology, 92: 11701182. https://doi.org/10.1086/228631

D'Andrea, A., Ferri, F. \& Grifoni, P. (2010). An overview of methods for virtual social networks analysis. In A. Abraham (Eds.), Computational social network analysis: 3-25. London: Springer. https://doi.org/10.1007/978-1-84882-229-0_1

de la Iglesia, J. L. M., \& Gayo, J. E. L. (2009). Doing business by selling free services. In M. Lytras, E. Damiani, \& P. Ordóñez de Pablos (Eds.), Web 2.0: 1-14. Boston: Springer. https://doi.org/10.1007/978-0-387-85895-1_6

Farrell, J., \& Klemperer, P. (2007). Coordination and lock-in: Competition with switching costs and network effect. In Handbook of Industrial Organization, vol. 3: 1967-2072. Elsevier. https://doi.org/10.1016/S1573-448X(06)03031-7

Gawer, A. \& Cusumano, M. A. (2002). Platform leadership: How Intel, Microsoft, and Cisco drive industry innovation. Boston: Harvard Business School Press.

Gawer, A. \& Cusumano, M. A. (2008). How companies become platform leaders. MIT Sloan Management Review, 49(2): 28-35.

Gawer, A. \& Cusumano, M. A. (2013). Industry platforms and ecosystem innovation. Journal of Production Innovation Management, 31: 417-433. https://doi.org/10.1111/jpim.12105

Grandjean, M. (2016). A social network analysis of Twitter: Mapping the digital humanities community, Cogent Arts \& Humanities, 3: 1171458. https://doi.org/10.1080/23311983.2016.1171458

Hanneman, R. A., \& Riddle, M. (2005). Introduction to social network methods. Riverside, CA, University of California. http://faculty.ucr.edu/ hanneman/. Accessed 22 August 2017.

lansiti, M., \& Levien, R. (2004). The keystone advantage: What the new dynamics of business ecosystems mean for strategy, innovation, and sustainability. Boston: Harvard University Press.

Katz, M. L., \& Shapiro, C. (1985). Network externalities, competition, and compatibility. American economic review, 75(3): 424-440. 
Kilduff, M., \& Brass, D. J. (2010). Organizational social network research: Core ideas and key debates. Academy of management annals, 4(1): 317-357. https://doi.org/10.5465/19416520.2010.494827

Leontief W. W. (1941). The structure of American economy, 1919-1929. Boston: Harvard University Press.

Moore, G. A. (1991). Crossing the chasm: Marketing and selling technology products to mainstream customers. New York: HarperCollins.

Moore, G. A. (2014). Crossing the chasm: Marketing and selling technology products to mainstream customers (3rd ed.). New York: HarperCollins.

Nasrinpour, H. R., \& Friesen, M. R. (2016). An agent-based model of message propagation in the Facebook electronic social network. arXiv preprint arXiv: 1611.07454.

Newman, M. E. J. (2010). Networks: An introduction. Oxford: Oxford University Press. https://doi.org/10.1093/acprof:oso/9780199206650.001.0001

Otte, E., \& Rousseau, R. (2002). Social network analysis: A powerful strategy, also for the information sciences. Journal of Information Science, 28: 441-453. https://doi.org/10.1177/016555150202800601

Pinheiro, C. A. R. (2011). Social network analysis in telecommunications. Hoboken, NJ: John Wiley \& Sons.

Porter, M. E., \& Heppelmann, J. E. (2014). How smart, connected products are transforming competition. Harvard Business Review, 92(11): 64-88.

Porter, M. E., \& Heppelmann, J. E. (2015). How smart, connected products are transforming companies. Harvard Business Review, 93(10): 96-114.

Reime, E. V. (2011). Exploring the freemium business model (Master's thesis). https://www.duo.uio.no/bitstream/handle/10852/12882/Reime.pdf. Accessed 17 December 2014.

Rochet, J. C., \& Tirole, J. (2003). Platform competition in two-sided markets. Journal of the European Economic Association, 1: 990-1029. https://doi.org/10.1162/154247603322493212

Rogers, E. M. (1962). Diffusion of innovations. Glencoe: New York: Free Press.

Rowley, T., Behrens, D., \& Krackhardt, D. (2000). Redundant governance structures: An analysis of structural and relational embeddedness in the steel and semiconductor industries. Strategic management journal, 21(3): 369-386. https://doi.org/10.1002/(SICI)1097-0266(200003)21:3<369::AIDSMJ93>3.0.CO;2-M

Vissa, B., \& Chacar, A. S. (2009). Leveraging ties: the contingent value of entrepreneurial teams' external advice networks on Indian software venture performance. Strategic Management Journal, 30(11): 1179-1191. https://doi.org/10.1002/smj.785 